\title{
Impact of Different Levels of Irrigation and Antitranspirant upon Wheat (Triticum aestivum L.) Physio-Biochemical and Economical Yield under Soil Application of Hydrogel
}

\author{
Anusha N. Reddy ${ }^{1}$, Richa Sharma ${ }^{1 *}$ and M. Sravani ${ }^{2}$ \\ ${ }^{1}$ Department of Biological sciences, Sam Higginbottom University of Agriculture, \\ Technology and Sciences, Allahabad 211007, UP, India \\ ${ }^{2}$ Department of Genetics and Plant Breeding, Lovely Professional University, \\ Jalandhar-144411, Punjab, India \\ *Corresponding author
}

\section{A B S T R A C T}

For efficient yield of any crop proper crop Irrigation is an important factor. Rainfall and irrigation are the two main sources of water in agriculture Current scenario of climate results in destructing rainfall pattern leading to different water stress. In some part of U.P,

\begin{tabular}{|c|}
\hline Keywords \\
\hline $\begin{array}{l}\text { Hydrogel, Chitosan } \\
\text { Water scarcity, } \\
\text { Level of irrigation }\end{array}$ \\
\hline Article Info \\
\hline $\begin{array}{l}\text { Accepted: } \\
\text { 24 August } 2018 \\
\text { Available Online: } \\
\text { 10 September } 2018\end{array}$ \\
\hline
\end{tabular}
especially eastern U.P. will face in temperature ( 3 to $5^{\circ} \mathrm{C}$ up to 2050) as per SAPCC, due to increase in rate of transpiration that will rise demand. To cope up with coming situation the experiment was conducted at Central Agricultural field, Sam Higginbottom University of Agriculture, Technology \& Sciences, U.P. on wheat variety (HD-2967). Hydrogel and Chitosan were taken under different concentration to evaluate the Efficacy of Pusa Hydrogel on Wheat (Triticum aestivum L.) Growth and Yield under Different Levels of Irrigation and Chitosan. Retaining the water in soil and by reducing the loss of water through stomata is the aspect to be considered to deal with such arriving future. Superabsorbent polymer can absorb large quantities of water and retain in soil and Antitranspirant may reduce the loss of water via transpiration. Hydrogel $(75 \%)$ and Chitosan $(100 \%, 75 \%$ and $50 \%)$ with twenty-five treatments and three replications along with control were laid out in randomized block design Result on crop growth and yield under water deficit condition was observed Treatment $\mathrm{T}_{1}$ (100\% HG and 100\% CHT) showed best results, however $T_{2}$ was statistically at par with $T_{1}$, whereas comparing with control $\mathrm{T}_{0}(100 \%$ IR $70 \mathrm{Lit}+\mathrm{NO} \mathrm{SAP}+\mathrm{NO}$ AT.

\section{Introduction}

Water is most importantly used for irrigation in agriculture which is key component to produce food. Irrigation accounts for more than $70 \%$ of total water withdrawals on a global basis (FAO, 2012a). Statistics exhibited that $25 \%$ of the world's agricultural land is now influenced by high levels of water stress (Alaei et al., 2010). Water stress is connected with almost all aspects of biology and plant growth It should pointed out that drought is one of the major causes of crop loss worldwide, which commonly reduces average yield for many crop plants by more than $50 \%$ (Shao et al., 2005). In some part of U.P, 
especially eastern U.P will face in temperature ( 3 to $5^{\circ} \mathrm{c}$ up to 2050 ) as per SAPCC which directly effects on agriculture production (SAPCC, 2014). Food productivity is decreasing due to the effect of various abiotic stresses therefore minimizing these loses is a major area of concern for all nations to cope with the increasing food requirements.

Wheat is the leading crop of the temperate climates of the world and a unique world food grain and it has grown on about 200 Million ha in a range of environments, with an annual production of more than 600 million metric tons (Plaut et al., 2004). On the other hand, global wheat production must continue to increase $2 \%$ annually until 2020 to meet future demands of imposed population and prosperity growth (Karam et al., 2009). There are various management practices through which water soil relationship can be maintained to make plant withstand water stress condition.

Hydrogel is one of the most popular, having also been used to reduce water runoff and increase infiltration rates in field agriculture, in addition to increasing water holding capacity for agricultural applications (Sharma, 2004). The use of hydrogels led to the significant decrease in the number of irrigations, especially for the soils with largescale texture (Koupai and Sohrab, 2004).

Antitranspirants are chemical compounds whose role is to train plants by gradually hardening them to stress as a method of reducing the impact of drought. There are different types of antitranspirants: filmforming which stops almost all transpiration; stomatic, which only affects the stomata; reflecting materials (Nasraui, 1993). Reducing transpiration can play a useful role in this respect by pre-venting the excessive loss of water to the atmosphere via stomata. The objective of this study was to understand the relationship of hydrogel applied to soil for better yield of wheat under different level of irrigation and chitosan.

\section{Materials and Methods}

Wheat variety (HD-2967), a local variety is taken as an experimental crop with different irrigation levels and chitosan. Over all 25 treatments (Table 1) has been undertaken with soil application hydrogel $(7 \mathrm{~kg} / \mathrm{ha})$. Different growth and yield parameters have been recorded and statistically analysed during the course of study

\section{Results and Discussion}

For Chlorophyll the treatments which were treated with Hydrogel and Chitosan were showing better result in comparison Control $(100 \%$ IR 70 Lit +NO SAP +NO AT) (1.68) Maximum Chlorophyll 'a' was observed in $\mathrm{T}_{1}$ (2.11) followed by $\mathrm{T}_{2}$ (2.03), $\mathrm{T}_{3}$ (1.96), $\mathrm{T}_{4}$ (1.89), $\mathrm{T}_{5}$ (1.86), $\mathrm{T}_{6}(1.85), \mathrm{T}_{7}$ (1.73) these treatments are showing better. Whereas, Minimum Chlorophyll 'a' was observed in $\mathrm{T}_{24}$ (0.68) (Table 2). Water stress effects on biochemical component of plant like chlorophyll, carotenoid and total chlorophyll of plant. The decrease in chlorophyll content under drought is a commonly observed phenomenon (Nikolaeva et al., 2010). The reduction in chlorophyll content under drought stress has been considered a typical indication of oxidative stress and may be the result of pigment photo-oxidation and chlorophyll degradation (Farooq et al., 2009). For relative water content all the treatment in which Hydrogel and chitosan is applied showing better results in comparison to water deficit condition. Control (100\% IR 70 Lit +NO SAP +NO AT) (70.09), Maximum Relative Water Content was observed in $\mathrm{T}_{1}(51.76 \%)$ followed by $\mathrm{T}_{2}(45.31 \%), \mathrm{T}_{3}(43.51 \%), \mathrm{T}_{4}$ (42.62\%), $\mathrm{T}_{5}(42.35 \%), \mathrm{T}_{6}(40.79 \%), \mathrm{T}_{7}$ $(39.57 \%)$ these treatments are showing better. 
whereas, Minimum Relative water Content was observed in $\mathrm{T}_{24}(28.31 \%)$ (Table 2). Relative water content (RWC) of leaves has been reported as direct indicator of plant water contents under water deficit conditions (Lugojan and Ciulca, 2011).

Drought stress leads to reduction of water status during crop growth, soil water potential and plant osmotic potential for water and nutrient uptake which ultimately reduce leaf turgor pressure which results in upset of plant metabolic activities. Antioxidant - Naturally there is a balance between antioxidant enzymes and reactive oxygen species (ROS) in a system. Any stress can disturb the balance which leads to an increase in the ROS amount, causing oxidative stress. Antioxidant enzyme levels increase to overcome ROS damage and bring cellular homeostasis back (Lee et al., 2007). For antioxidant Proline and Superoxide dismutase (SOD) treatments under water stress are showing higher level Proline and superoxide dismutase level the highest level was found in15 DAS (4 ${ }^{\text {th }}$ Irrigation) Maximum Proline was observed in $\mathrm{T}_{24}(0.31$ $\mathrm{gm})$ followed by $\mathrm{T}_{23}(0.28 \mathrm{gm}), \mathrm{T}_{22}(0.26 \mathrm{gm})$, $\mathrm{T}_{21}(0.23 \mathrm{gm}), \mathrm{T}_{20}(0.21 \mathrm{gm}), \mathrm{T}_{19}(0.20 \mathrm{gm})$, whereas, Minimum Proline was observed in $\mathrm{T}_{1}$ (0.08 gm) (Table 3).

\section{Table.1 Treatment Details}

\begin{tabular}{|c|c|}
\hline Treatments & Treatment combination \\
\hline $\mathrm{T}_{0}$ & $100 \%$ IR 70 Lit +NO SAP +NO AT \\
\hline$T_{1}$ & $80 \%$ IR (56 Lit) +100\% AT (250ppm) +75\% HG (1 gm) \\
\hline$\overline{T_{2}}$ & $80 \%$ IR (56 Lit) +100\% AT (250ppm) +NO SAP \\
\hline $\mathbf{T}_{3}$ & $80 \%$ IR (56 Lit) +75\% AT (187ppm) +75\% HG (1 gm) \\
\hline $\mathbf{T}_{4}$ & $80 \%$ IR 56 Lit + 75\% AT (187ppm) + NO SAP \\
\hline$T_{5}$ & $80 \%$ IR (56 Lit) +50\% AT (125ppm) + 75\% HG (1 gm) \\
\hline$T_{6}$ & $80 \%$ IR (56 Lit) +50\% AT (125ppm) + NO SAP \\
\hline $\mathbf{T}_{7}$ & $80 \%$ IR (56 Lit) +NOAT + 75\% HG (1 gm) \\
\hline $\mathbf{T}_{8}$ & $80 \%$ IR (56 Lit) + NOAT +NO SAP \\
\hline$T_{9}$ & $60 \%$ IR (42 Lit) +100\% AT (250ppm) +75\% HG (1) gm \\
\hline$\overline{T_{10}}$ & $60 \%$ IR (42 Lit) +100\% AT (250ppm) + NO SAP \\
\hline$T_{11}$ & $60 \%$ IR (42 Lit) +75\% AT (187ppm) +75\% HG (1 gm) \\
\hline$T_{12}$ & $60 \%$ IR (42 Lit) +75\% AT (187ppm) + NO SAP \\
\hline$\overline{T_{13}}$ & $60 \%$ IR (42 Lit) +50\% AT (125ppm) +75\% HG (1. gm) \\
\hline$\frac{T_{14}}{1}$ & $60 \%$ IR (42 Lit) +50\% AT (125ppm) +NO SAP \\
\hline$T_{15}$ & $60 \%$ IR (42 Lit) + NOAT+75\% HG (1 gm) \\
\hline$T_{16}$ & $60 \%$ IR (42 Lit) + NOAT+NO SAP \\
\hline$T_{17}$ & $40 \%$ IR (28 Lit) +100\% AT (250ppm) +75\% SAP (1 gm) \\
\hline$T_{18}$ & $40 \%$ IR (28 Lit) + 100\% AT 250ppm + NOSAP \\
\hline$T_{19}$ & $40 \%$ IR (28 Lit) +75\% AT (187ppm) +75\% HG (1 gm) \\
\hline$T_{20}$ & $40 \%$ IR (28 Lit) +75\% AT (187ppm) +NO SAP \\
\hline$T_{21}$ & $40 \%$ IR (28 Lit) +50\% AT (125ppm) +75\% HG (1 gm) \\
\hline $\mathbf{T}_{22}$ & $40 \%$ IR (28 Lit) +50\% AT (125ppm) +NO SAP \\
\hline$T_{23}$ & 40\% IR (28 Lit) +NOAT + 75\% SAP (1 gm) \\
\hline $\mathbf{T}_{24}$ & 40\% IR (28 Lit) +NOAT+ NOSAP \\
\hline
\end{tabular}


Table.2 Impact of Different levels of Irrigation and Antitranspirant on Chlorophyll 'a' (mg/g fw), Chlorophyll 'b' (mg/g fw), Carotenoids (mg/g fw), Relative Water Content (\%) upon Wheat (Triticum aestivum L.) Physio-biochemical and Economical Yield under Soil Application of Hydrogel

\begin{tabular}{|c|c|c|c|c|}
\hline Treatments & Chlorophyll ' $a$ ' (mg/g fw) & Chlorophyll 'b' (mg/g fw) & Carotenoids (mg/g fw) & Relative Water Content (\%) \\
\hline $\mathrm{T}_{0}$ & 1.68 & 1.59 & 2.11 & 38.47 \\
\hline $\mathbf{T}_{1}$ & 2.11 & 2.00 & 2.76 & 51.76 \\
\hline $\mathbf{T}_{2}$ & 2.03 & 1.94 & 2.34 & 45.31 \\
\hline $\mathrm{T}_{3}$ & 1.96 & 1.86 & 2.32 & 43.51 \\
\hline $\mathbf{T}_{4}$ & 1.89 & 1.79 & 2.17 & 42.62 \\
\hline $\mathbf{T}_{5}$ & 1.86 & 1.76 & 2.15 & 42.35 \\
\hline $\mathrm{T}_{6}$ & 1.85 & 1.69 & 2.13 & 40.79 \\
\hline $\mathbf{T}_{7}$ & 1.73 & 1.63 & 2.13 & 39.57 \\
\hline $\mathbf{T}_{8}$ & 1.66 & 1.56 & 2.12 & 37.73 \\
\hline $\mathrm{T}_{9}$ & 1.64 & 1.54 & 2.11 & 36.24 \\
\hline $\mathbf{T}_{10}$ & 1.37 & 1.27 & 2.07 & 35.33 \\
\hline $\mathbf{T}_{11}$ & 1.36 & 1.26 & 2.06 & 33.48 \\
\hline$T_{12}$ & 1.33 & 1.23 & 2.03 & 33.36 \\
\hline$T_{13}$ & 1.30 & 1.20 & 2.03 & 32.73 \\
\hline $\mathbf{T}_{14}$ & 1.30 & 1.20 & 1.97 & 32.67 \\
\hline$T_{15}$ & 1.27 & 1.17 & 1.94 & 32.54 \\
\hline$T_{16}$ & 1.26 & 1.16 & 1.92 & 32.51 \\
\hline $\mathbf{T}_{17}$ & 1.22 & 1.12 & 1.85 & 32.43 \\
\hline$T_{18}$ & 1.20 & 1.10 & 1.81 & 32.42 \\
\hline$T_{19}$ & 1.14 & 1.03 & 1.68 & 31.76 \\
\hline $\mathbf{T}_{20}$ & 1.13 & 1.03 & 1.67 & 30.71 \\
\hline $\mathbf{T}_{21}$ & 1.11 & 1.01 & 1.63 & 30.36 \\
\hline$T_{22}$ & 1.10 & 1.00 & 1.62 & 29.78 \\
\hline $\mathbf{T}_{23}$ & 0.87 & 0.77 & 1.15 & 29.51 \\
\hline $\mathbf{T}_{24}$ & 0.68 & 0.68 & 0.96 & 28.31 \\
\hline Mean & 2.11 & 1.59 & 1.94 & 35.54 \\
\hline C.D. & 0.189 & 0.209 & 0.002 & 1.362 \\
\hline $\mathrm{SE}(\mathbf{m})$ & 0.066 & 0.73 & 0.001 & 0.478 \\
\hline F-test & Significant & Significant & Significant & Significant \\
\hline
\end{tabular}


Table.3 Impact of Different levels of Irrigation and Antitranspirant on Proline (mg/g fw), Superoxide dismutase (mg/g fw), Economical yield (q/ha ${ }^{-1}$ ), Test Weight (gm) upon Wheat (Triticum aestivum L.) Physio-biochemical and Economical Yield under Soil Application of Hydrogel

\begin{tabular}{|c|c|c|c|c|}
\hline Treatments & Proline (mg/g fw) & Superoxide dismutase (mg/g fw) & Economical yield $\left(q / h^{-1} a^{-1}\right.$ & Test weight (gm) \\
\hline $\mathbf{T}_{0}$ & 0.12 & 0.55 & 32.68 & 27.8 \\
\hline $\mathbf{T}_{1}$ & 0.08 & 0.28 & 89.19 & 43.3 \\
\hline $\mathbf{T}_{2}$ & 0.10 & 0.4 & 65.97 & 42.8 \\
\hline $\mathbf{T}_{3}$ & 0.11 & 0.42 & 47.77 & 31.9 \\
\hline $\mathbf{T}_{4}$ & 0.12 & 0.48 & 40.17 & 31.7 \\
\hline $\mathbf{T}_{5}$ & 0.13 & 0.5 & 39.97 & 31.1 \\
\hline $\mathrm{T}_{6}$ & 0.13 & 0.53 & 39.47 & 30.6 \\
\hline $\mathrm{T}_{7}$ & 0.14 & 0.54 & 33.87 & 27.9 \\
\hline $\mathrm{T}_{8}$ & 0.14 & 0.56 & 32.37 & 27.6 \\
\hline $\mathrm{T}_{9}$ & 0.15 & 0.58 & 31.67 & 25.6 \\
\hline$T_{10}$ & 0.15 & 0.6 & 31.43 & 24.4 \\
\hline$\overline{T_{11}}$ & 0.15 & 0.62 & 31.28 & 24.3 \\
\hline$T_{12}$ & 0.16 & 0.64 & 30.27 & 23.6 \\
\hline$T_{13}$ & 0.16 & 0.71 & 28.28 & 22.9 \\
\hline$T_{14}$ & 0.16 & 0.76 & 27.93 & 22.7 \\
\hline$T_{15}$ & 0.17 & 0.88 & 27.87 & 22.1 \\
\hline $\mathbf{T}_{16}$ & 0.18 & 0.99 & 27.4 & 21.9 \\
\hline$T_{17}$ & 0.18 & 1.03 & 27.33 & 21.6 \\
\hline$T_{18}$ & 0.19 & 1.08 & 25.86 & 21.6 \\
\hline $\mathrm{T}_{19}$ & 0.20 & 1.11 & 25.43 & 21.2 \\
\hline $\mathbf{T}_{20}$ & 0.21 & 1.53 & 23.91 & 21.1 \\
\hline $\mathbf{T}_{21}$ & 0.23 & 1.59 & 23.74 & 21.0 \\
\hline$T_{22}$ & 0.26 & 1.72 & 23.33 & 21.0 \\
\hline $\mathbf{T}_{23}$ & 0.28 & 1.78 & 22.33 & 20.5 \\
\hline $\mathbf{T}_{24}$ & 0.31 & 1.85 & 21.12 & 20.1 \\
\hline Mean & 0.1684 & 1.5004 & 33.99 & 26.01 \\
\hline C.D. & 0.010 & 0.064 & 36.391 & 1.220 \\
\hline SE(m) & 0.004 & 0.022 & 12.781 & 0.429 \\
\hline F-test & Significant & Significant & Significant & Significant \\
\hline
\end{tabular}


There was an inverse relationship between drought severity and proline content, which create a defence mechanism in stressed in order to control osmotic pressure (Wang, 2003). Proline is well known to occur extensively in higher crop plants and accumulates in higher concentration in response to different abiotic environmental stresses specially drought stress (Kishore et al., 2005). Superoxide dismutase (SODs) is ubiquitous metalloenzymes that catalyze the dismutation of superoxide radical to $\mathrm{H} 2 \mathrm{O} 2$ and $\mathrm{O}_{2}$. The superoxide radical is a potential precursor of the highly oxidizing hydroxyl radical and, therefore, SODs are a critical defence of plants, other aerobic organisms, and some anaerobes against oxidative stress (Halliwell and Gutteridge, 1999). Plants under water deficit stress showed a significant increase in SOD, CAT and GPX activities of canola leaves compared with control plants (Mohaddam et al., 2009) 15 DAS (4 Irrigation) Maximum Superoxide dismutase was observed in $\mathrm{T}_{24}$ (1.85) followed by $\mathrm{T}_{23}$ (1.78), $\mathrm{T}_{22}$ (1.72), $\mathrm{T}_{21}$ (1.59), $\mathrm{T}_{20}$ (1.53), $\mathrm{T}_{19}$ (1.11), $\mathrm{T}_{18}$ (1.08) whereas, Minimum Superoxidedismutase was observed in $\mathrm{T}_{1}(0.28)$ (Table 3) grain yield, all the treatments in which Hydrogel and chitosan is applied were showing better results in comparison to water deficit conditionMaximum Grain yield was observed in $\mathrm{T}_{1}\left(89.1 \mathrm{q} / \mathrm{ha}^{-1}\right)$ whereas, Minimum Grain Yield was observed in $\mathrm{T}_{24}$ (21.12 q/ha' $\left.{ }^{-1}\right)$. Table No: 3. Due to water shortage, the ability of absorbing nutrients, composing and transferring assimilate is decreased that leads to a reduction in biological yield (Kisman, 2003). The results of many researches show that drought stress at different stages of the growth wheat under different levels Irrigations and Chitosan. lead to a reduction in the yield of Economic yield components wheat under different levels Irrigations and Chitosan (Gooding et al., 2003; Garcia et al., 2003 and Zaharieva et al., 2001). 1000 grain weights of all the treatments which were treated with Hydrogel and Chitosan were showing better result in $\mathrm{T}_{1}$ than comparison to Control (100\% IR 70 Lit +NO SAP +NO AT) (Gooding et al., 2003) in their studies on intensity and duration of water stress on wheat reported that drought stress reduced grain yield and 1000-grain weight by shortening the grain formation period. Khan et al., (2005) and Qadir et al., (1999) observed that 1000-grain weight wheat under different levels Irrigations and Chitosan, was reduced mainly due to increasing water stress.

Under Agro climatic condition of Allahabad This study may conclude that $\mathrm{T}_{1}$ is performing best for all the absorbed parameters with Chlorophyll 'a', Chlorophyll 'b', Carotenoids, Relative Water Content, Yield and Test Weight maximum yield $\left(89.19 \mathrm{q} / \mathrm{ha}^{-}{ }^{1}\right)$ Minimum performance was showed by $\mathrm{T}_{24}$ yield $\left(21.12 \mathrm{q} / \mathrm{ha}^{-1}\right)$ Whereas in Proline, Superoxide dismutase under stress condition treatments are showing better in $\mathrm{T}_{24}$ than $\mathrm{T}_{1}$. Recommendation: $\mathrm{T}_{1}, \mathrm{~T}_{2}, \mathrm{~T}_{3}, \mathrm{~T}_{4}, \mathrm{~T}_{5}, \mathrm{~T}_{6}, \mathrm{~T}_{7}$. from all treatments are performing well, according to requirement and retention capacity of the soil any of these treatments can be adopted by the farmer.on the basis of cost benefit analysis following treatments are performing better comparison to $\mathrm{T}_{0}$, thus on the basis of soil condition and availability of water any of these can be adopted by the farmer.

\section{References}

Alaei, M., Zaefizadeh, M., Khayatnezhad, M., Alaei, Z and Alaei, Y, 2010, Evaluation of germination properties of different durum Wheat genotypes under osmotic stress, Middle- East J. Sci. Res., 6, 642646.

FAO, (2012a). Coping with water scarcity. FAO Water Report 38. Rome, Italy. 
Farooq, M., A. Wahid, N. Kobayashi, D. Fujita and S.M.A. Basra, 2009, Plant drought stress: effects, mechanisms and management. Agron. Sustain. Dev., 29: 185-212.

Garcia, D., Moral, L.F., Rharrabt, Y., Villegas, D and Royo, C (2003). Evaluation of grain yield and its components in durum wheat under Mediterranean condition, Agronomy Journal. 95: 266-274.

Garcia, D., Moral, L.F., Rharrabt, Y., Villegas, D and Royo, C (2003). Evaluation of grain yield and its components in durum wheat under Mediteranean condition, Agronomy Journal. 95: 266-274.

Gooding, M. J., Ellis, R.H., Shewry P. R and Schofield, J. D (2003). Effects of restricted water availability and increased temperature on grain formation, drying and quality of water wheat, Journal of cereal Sciences 37: 295-309.

Gooding, M. J., Ellis, R.H., Shewry P. R and Schofield, J. D (2003). Effects of restricted water availability and increased temperature on grain formation, drying and quality of water wheat, Journal of cereal Sciences 37: 295-309.

Halliwell B, Gutteridge JMC (1999) Free Radicals in Biology and Medicine. 3rd Ed. Oxford University Press, New York, 936 pp.

Karam, F., Kabalan, R., Breidi, J., RouHGael, Y., and Oweis, T., 2009, Yield and water- production functions of two durum wheat cultivars grown under different irrigation and nitrogen regimes, Agricultural Water Management, 96(4): 603-615.

Khan, A.J., F. Azam A. Ali, M. Tariq and M. Amin (2005). Inter-relationship and path co-efficient analysis for biometric traits in drought tolerant wheat
(Triticum aestivum L.). Asian Journal of Plant Sciences, 4(5): 540-543.

Khan, A.J., F. Azam A. Ali, M. Tariq and M. Amin (2005). Inter-relationship and path co-efficient analysis for biometric traits in drought tolerant wheat (Triticum aestivum L.). Asian Journal of Plant Sciences, 4(5): 540-543.

Kishor PBK, Hong ZL, Miao GH, Hu CAA, Verma DPS. 1995. Overexpression of delta-pyrroline-5-carboxylate synthetase increases proline production and confers osmotolerance in transgenic plants. Plant Physiology 108, 1387-1394.

Kisman, A (2003). Effects of drought stress on growth and yield of soybean, Sci Phil. Term paper. Borgor Agric. Univ. (Institute Pertanian Borgor).

Koupai, A.J and Sohrab, F (2004). Effect evaluation of superabsorbent application on water retention capacity and water potential in three soil textures. J. Sci. Technol. Polym, 17(3): 163-173.

Lee, K. P., Kim, C., Landgraf, F., and Apel, K. (2007). EXECUTER1-and EXECUTER2-dependent transfer of stress-related signals from the plastid to the nucleus of Arabidopsis thaliana. Proc. Natl. Acad. Sci. U.S.A. 104, 10270-10275. doi: 10.1073/pnas. 0702061104

Lugojan C \& Ciulca S (2011) Evaluation of relative water content in winter wheat. Journal of Horticulture Forestry Biotechnology 15: 173-177.

Mohammad, S., and Fardin, G. (2012). Effects of super absorbent polymer a200 on the growth, yield and some physiological responses in sweet pepper (Capsicum annuum L.) under various irrigation regimes. International Journal of Agricultural and Food Research. 1(1): 1- 11.

Nasraui, B., 1993, Role of antitranspirant films in protecting plants against fun- 
gal disease. Annals de l'Institute National de la Recherche Agronomique deTunisie 66, 125-135.

Nikolaeva, M. K., Maevskaya, S. N., Shugaev, A. G. and Bukhov, N. G. (2010), Effect of drought on chlorophyll content and antioxidant enzyme activities in leaves of three wheat cultivars varying in productivity. Russ. J. Plant Physiol. 57: 87-95.

Plaut, Z., Butow, B.J., Blumenthal, C.S., and Wrigley, C.W., 2004, Transport of dry matter into developing wheat kernels and its contribution to grain yield under post-anthesis water deficit and evaluated temperature, Field Crops Res., 86, 185-198.

Qadir G., Mohammad, S and Cheema, M. A (1999). Effect of water stress on growth and yield performance of four wheat cultivars. Pak. Journal of Biological Sciences. 2(1): 236-239.

Shao, H.B., Liang, Z.S., and Shao, M.A., 2005, Changes of anti-oxidative enzymes and MDA content under soil water deficits among 10 wheat (Triticum aestivum L.) genotypes at maturation stage, Colloids Surf. $B$ : Biointerfaces, 45, 7-13.

Sharma J. Establishment of perennials in hydroHGilic polymer-amended soil. SNA Research Conference.2004; 42:530-32.

Uttar Pradesh State Action Plan on Climate Change. Department of Environment (with support from giZ and CTRAN Consulting): CNTR NO 83181079. (SPACC)

Wang, W., Vinocur, B., and Altman, A. (2003). Plant responses to drought, salinity and extreme temperatures: towards genetic engineering for stress tolerance. Planta 218, 1-14. doi: 10.1007/s00425-003-1105-5.

Zaharieva, M., Gaulin, E., Havaux, M., Acevedo, E and Monneveux, P (2001). Drought and heat responses in the wild wheat relative Aegilops geniculata Roth, Crop Science. 14: 1321-1329.

\section{How to cite this article:}

Anusha N. Reddy, Richa Sharma and Sravani, M. 2018. Impact of Different Levels of Irrigation and Antitranspirant upon Wheat (Triticum aestivum L.) Physio-Biochemical and Economical Yield under Soil Application of Hydrogel. Int.J.Curr.Microbiol.App.Sci. 7(09): 3361-3368. doi: https://doi.org/10.20546/ijcmas.2018.709.417 